\title{
Altered hepatic gene expression in non-alcoholic fatty liver disease is associated with lower hepatic n-3 and n-6 polyunsaturated fatty acids
}

\author{
Bianca M. Arendt ${ }^{1}$, Elena M. Comelli ${ }^{2}$, David W. L. Ma ${ }^{3}$, Wendy Lou ${ }^{4}$, Anastasia Teterina ${ }^{1}$, \\ TaeHyung Kim ${ }^{5,6}$, Scott K. Fung ${ }^{1,7}$, David K. H. Wong ${ }^{7,8}$, Ian McGilvray ${ }^{1,9}$, Sandra E. Fischer ${ }^{1,10}$, \\ Johane P. Allard ${ }^{1,7}$
}

${ }^{1}$ Toronto General Hospital, University Health Network, Toronto, ON, Canada

${ }^{2}$ Department of Nutritional Sciences, University of Toronto, Toronto, ON, Canada

${ }^{3}$ Department of Human Health and Nutritional Sciences, University of Guelph, Guelph, ON, Canada

${ }^{4}$ Dalla Lana School of Public Health, University of Toronto, Toronto, ON, Canada

${ }^{5}$ Department of Computer Sciences, University of Toronto, Toronto, ON, Canada

${ }^{6}$ Donnelly Centre for Cellular and Biomolecular Research, Department of Molecular

Genetics,

University of Toronto, Toronto, ON, Canada

${ }^{7}$ Department of Medicine, University of Toronto, Toronto, ON, Canada

${ }^{8}$ Toronto Western Hospital, University Health Network, Toronto, ON, Canada

${ }^{9}$ Department of Surgery, University of Toronto, Toronto, ON, Canada

${ }^{10}$ Department of Laboratory Medicine and Pathobiology, University of Toronto, Toronto, ON, Canada

Email:

Bianca M. Arendt: $\underline{\text { barendt@uhnresearch.ca }}$

Elena M.Comelli: elena.comelli@utoronto.ca

David W. L. Ma: davidma@uoguelph.ca

Wendy Lou: wendy.lou@utoronto.ca

Anastasia Teterina: anastasia.teterina@uhnresearch.ca 
TaeHyung Kim: taehyung.kim@mail.utoronto.ca

Scott K. Fung: scott.fung@uhn.ca

David K. H. Wong: dave.wong@uhn.on.ca

Ian McGilvray: ian.mcgilvray@uhn.ca

Sandra E. Fischer: dr.sandra.fischer@uhn.ca

Johane P. Allard: johane.allard@uhn.on.ca

\section{Keywords}

steatohepatitis, microarray, human, fatty acid desaturase, essential fatty acids 


\section{FOOTNOTE PAGE}

\section{Contact Information}

Corresponding Author: Johane P. Allard

Dept. of Medicine, University Health Network

585 University Ave, Suite 9-NU-973

Toronto, ON, M5G 2C4, Canada

Email: johane.allard@uhn.on.ca

Phone: +1-416-340-5159

Fax: +1-416-348-0065

\section{List of Abbreviations}

NAFLD, nonalcoholic fatty liver disease; NASH, nonalcoholic steatohepatitis; HCC:

hepatocellular carcinoma; SS, simple steatosis; FA, fatty acid; PUFA, polyunsaturated fatty acid; HC, healthy controls; FDR, false-discovery rate; DEG, differentially expressed genes; EPA, eicosapentaenoic acid; DHA, docosahexaenoic acid; AA, arachidonic acid; HOMA-IR, Homeostasis model of assessment for insulin resistance; BMI, body mass index; PCA, principal component analysis; ANCOVA, analysis of covariance

\section{Financial Support}

This study was funded through operating grants from the Canadian Institutes of Health Research (NMD-86922, MOP-89705) and the American College of Gastroenterology, a student research fellowship award from American Gastroenterological Association, and a summer studentship from the Canadian Liver Foundation. 


\begin{abstract}
In nonalcoholic fatty liver disease (NAFLD), hepatic gene expression and fatty acid (FA) composition have been reported independently but a comprehensive gene expression profiling in relation to FA composition is lacking. The aim was to assess this relationship. In a cross-sectional study, hepatic gene expression (Illumina Microarray) was first compared among 20 patients with simple steatosis (SS), 19 with nonalcoholic steatohepatitis (NASH), and 24 healthy controls (HC). FA composition in hepatic total lipids was compared between SS and NASH, and associations between gene expression and FA were examined. Gene expression differed mainly between $\mathrm{HC}$ and patients (SS and NASH), including genes related to unsaturated FA metabolism. Twenty-two genes were differentially expressed between NASH and SS; most of them correlated with disease severity and related more to cancer progression than to lipid metabolism. Biologically long-chain polyunsaturated FA (PUFA) (eicosapentaenoic acid + docosahexaenoic acid, arachidonic acid) in hepatic total lipids were lower in NASH than in SS. This may be related to overexpression of FADS1, FADS2, and PNPLA3. The degree and direction of correlations between PUFA and gene expression were different among SS and NASH which may suggest that low PUFA content in NASH modulates gene expression in a different way compared with SS or, alternatively, gene expression influences PUFA content differently depending on disease severity (SS versus NASH). Conclusion: Well-defined subjects with either healthy liver, SS or NASH showed distinct hepatic gene expression profiles including genes involved in unsaturated FA metabolism. In NASH, hepatic PUFA were lower and associations with gene expression were different than in SS.
\end{abstract}


Nonalcoholic fatty liver disease (NAFLD) is associated with excessive energy and fat intake, insulin resistance, and/or altered lipid metabolism (1). About 10-15\% of patients have nonalcoholic steatohepatitis (NASH), which can progress to cirrhosis and hepatocellular carcinoma (HCC) (2,3). Altered hepatic gene expression has been reported in NAFLD, including genes involved in lipid metabolism, apoptosis, liver generation, fibrosis, alcohol and drug metabolism, and detoxification (4-8). In addition, gene expression differs between NAFLD patients with or without fibrosis (9) and between simple steatosis (SS) and NASH, where main differences occurred for transcription factors, oxidative stress response, fibrosis, apoptosis, insulin signaling and metabolism related genes $(5,6,10,11)$.

Hepatic gene expression can be altered in response to the type of fatty acids (FA) consumed, especially the relative amount of long-chain n-6 and n-3 polyunsaturated FA (PUFA) $(12,13)$. These PUFA can modulate lipogenesis, insulin resistance, and inflammation, mainly through interaction with transcription factors (12). Reduced n-3 and n-6 PUFA in hepatic total lipids and triacylglycerols were reported in patients with NAFLD, especially those with NASH compared to controls (14-16), consistent with low dietary PUFA intakes $(17,18)$. Improvement of hepatic steatosis with n-3 PUFA supplementation has also been described (19), suggesting that low n-3 PUFA intake may contribute to NAFLD pathogenesis. In addition, dysregulation of gene expression and oxidative stress observed in NALFD could contribute to PUFA depletion in the liver (15,20). Although associations between hepatic total lipid PUFA and the expression of single genes have been described $(20,21)$, there are no studies broadly examining the association between FA composition and global gene expression, in particular related to lipid metabolism, oxidative stress, inflammation, and fibrosis in these patients. Thus, the aim was to a) compare hepatic gene expression among well characterized groups of participants with healthy liver, SS or NASH; and b) examine in SS and NASH, the relationship between long-chain PUFA in hepatic total lipids and expression levels of genes that might contribute to the disease phenotype. Oxidative stress and diet were also assessed.

\section{Methods}

Between March 2007 and November 2011, patients and healthy controls (HC) were recruited

from the liver clinic or the Multiorgan Transplant Program respectively, at the University Health 
Network, Toronto, Canada. The study was approved by the local Research Ethics Board, registered (NCT02148471, www.clinicaltrials.gov), and it followed the guidelines of the 1975 Declaration of Helsinki and its revisions. All participants provided informed written consent. No organs were obtained from executed prisoners or other institutionalized persons.

Patients were approached when a liver biopsy for suspected NAFLD was scheduled; HC were approached during their assessments for a live donor liver transplant. These participants underwent transient elastography, computed tomography, and/or medical resonance imaging. Inclusion criteria were: male or female, $\geq 18$ years; for $\mathrm{HC}$, presence of a normal liver (no steatosis or cirrhosis) on imaging and/or histology and for NAFLD patients, a diagnostic liver biopsy. Exclusion criteria were: alcohol consumption >20g/d; any other liver disease; use of medications that may cause steatohepatitis, ursodeoxycholic acid or any experimental drug, antioxidants or PUFA supplements in the 6 months prior to entry; pregnancy or breastfeeding. In addition for NAFLD patients: anticipated need for liver transplantation within one year, complications of liver disease, or any reasons contraindicating a biopsy; for HC: any reason excluding them from liver donation. Liver tissue was collected during percutaneous needle biopsy (NAFLD) or as a wedge biopsy during hepatectomy (HC) and was divided in three parts to be stored in 10\% formalin for histology; in RNAlater (Qiagen, Hilden, Germany) for gene expression analysis; or at $-80{ }^{\circ} \mathrm{C}$ for FA analysis. Participants provided one fasting blood sample and completed a 7 -day food record and activity log. Anthropometric and clinical data were collected.

Liver histology: Samples were stained with hematoxylin and eosin for morphologic evaluation and Prussian Blue to rule out iron loading. A single pathologist reviewed the slides (SEF). SS or NASH were diagnosed according to Brunt (22), and the NAFLD activity score was assessed (23).

Hepatic gene expression: Total RNA was extracted from liver biopsies using the $\operatorname{mirVana}^{\mathrm{TM}}$ miRNA Isolation kit (Life Technologies Corp., Carlsbad, CA, USA); RNA concentration, purity, and quality were assessed spectrophotometrically and with an Agilent BioAnalyzer (Agilent, Santa Clara, CA) (Supplementary Methods). Two hundred nanograms RNA were used for 
analysis with the Whole Genome Gene DASL HT Assay (Illumina Inc., San Diego, CA, USA) and the Illumina Human HT-12 V4 BeadChip, which covers 29,285 probes of the $>47,000$ annotated transcripts from the National Center for Biotechnology Information Reference Sequence (RefSeq) database (24) (Release 38, November 2009) (Supplementary Methods). Data was checked for overall quality using R (v2.15.1) with the lumi Bioconductor package (25). Nine outliers (4 NASH, $5 \mathrm{SS}$ ), which fell below the threshold for one or more of the quality metrics calculated with this package, were excluded from further analysis. The data were imported in GeneSpring v12.5 (Agilent) and normalized using a quantile normalization followed by a "per probe" median centered normalization. All analysis and visualization were performed on $\log 2$ transformed data. Data was first filtered to remove the probes that showed no signal and only 22,461 probes that were in the upper $80^{\text {th }}$ percentile of the distribution of intensities in at least $80 \%$ of the samples in any of the three groups were retained.

Differentially expressed genes (DEG) were identified by one way ANOVA with a BenjaminiHochberg false-discovery rate (FDR) $\mathrm{q}<0.05$ and Tukey HSD post-hoc test. Expression profiles were clustered for visualization using a Pearson centered correlation as a distance metric with average linkage rules in the tree building algorithm. DEG were filtered for at least 2.0 fold up- or down-regulation. A functional annotation and gene ontology enrichment analysis was performed using the DAVID Bioinformatics Resources 6.7 (26,27). In addition, gene lists were created for NAFLD relevant processes: fibrosis, chronic inflammatory response, cellular response to oxidative stress, lipogenesis, beta-oxidation, and long-chain and unsaturated FA metabolism (Supplementary Table S1). Due to limited liver tissue, confirmation of the results by real-time polymerase chain reaction was not possible. Several studies have previously shown consistency between differential gene expression measured by microarray and polymerase chain reaction and confirmation is no longer considered essential $(28,29)$.

Hepatic oxidative stress and fatty acids. Liver tissue was homogenized in phosphate-buffered saline with butylated hydroxytoluene as antioxidant. Commercial kits were used to assess antioxidant power (TA02, Oxford Biomedical Research, Oxford, MI) and lipid peroxidation (Bioxytech LPO-586, Oxis International, Portland, OR). 
Total lipids from $250 \mu \mathrm{L}$ of the same homogenate were extracted in chloroform/methanol (30) and analyzed using gas chromatography (14,30,31) (Supplementary Methods). The relative amount of single FA was calculated as \% of total lipids. Due to the small amount of tissue available for NAFLD, a separation into lipid sub-fraction was not possible. As patients with NAFLD have higher tri- and diacylglycerols and lower phosphatidylcholine than HC and these lipid sub-fractions can have different FA composition $(15,16)$, we compared hepatic FA only between NASH and SS, who are both characterized by triacylglycerol accumulation in the liver.

Blood biochemistry and nutritional assessment. Plasma and serum were collected after 8hours fast. Liver function tests, lipid profile, glucose, insulin, hemoglobin A1c, and C-peptide were measured using standard procedures (Supplementary Methods). Homeostasis model of assessment for insulin resistance (HOMA-IR) was calculated (32). Erythrocytes were separated from EDTA plasma; lipids were extracted and FA measured by gas chromatography (Supplementary Methods). Body mass index $\left(\mathrm{BMI}=\right.$ weight $\left.(\mathrm{kg}) /[\text { height }(\mathrm{cm})]^{2}\right)$ and waist circumference were measured. Diet was assessed by 7-day food records, using Food Portion Visual (Nutrition Consulting Enterprises, Framingham, MA) for portion size estimation and Food Processor SQL (ESHA Research, Salem, OR) for nutrient analysis. Participants recorded duration and intensity of physical activity for one week (33).

Statistical Analysis. Gene expression analysis is described above. For sensitivity analysis of BMI influence on gene expression, a nested ANOVA where disease groups were compared within BMI categories $\left(\mathrm{BMI}<25 \mathrm{~kg} / \mathrm{m}^{2}\right.$, normal weight; $25 \leq \mathrm{BMI}<30 \mathrm{~kg} / \mathrm{m}^{2}$, overweight; BMI $\geq 30 \mathrm{~kg} / \mathrm{m}^{2}$, obese) was used. Other results are presented as mean $\pm \mathrm{SD}$, median (interquartile range), or \% of cases. Continuous variables were compared among groups by ANOVA with Tukey's post-hoc test, t-test, or Wilcoxon test, depending on the distribution (Shapiro Wilks test). Chi square and Fisher's exact tests were applied for categorical variables. A principal component analysis (PCA) was conducted to reduce the dimensionality of the dataset. It was performed separately for five gene sets: fibrosis; chronic inflammation/response to oxidative stress; lipogenesis/beta-oxidation; long-chain/unsaturated FA metabolism; and genes that differed between NASH and SS. The relations between genes, FA, and clinical parameters were examined by Spearman correlation. In order to test the significance of differences in 
relationships of genes and FA between SS and NASH, analysis of covariance (ANCOVA) was employed. (SAS Enterprise Guide 4.3, SAS Institute Inc, Cary, NC, USA). p<0.05 was considered significant.

\section{Results}

Clinical characteristics and oxidative stress. Data from 63 participants were included in the study (20 SS, 19 NASH, 24 HC) (Supplementary Figure S1). A subgroup of patients had hepatic $(n=28)$ and erythrocyte FA $(n=16)$ measured. The groups did not differ for age, sex, race/ethnicity or alcohol intake, but the NASH group had more smokers than HC (Table 1). Patients, especially those with NASH, had higher BMI and waist circumference than HC. Liver histology showed increasing disease severity from SS to NASH (Table 1). Hepatic oxidative stress measures did not differ among the groups (Table 1). Liver transaminases, fasting insulin, C-peptide, triacylglycerols and HOMA-IR were higher in patients compared with HC and, except for triacylglycerols, also higher in NASH than in SS (Supplementary Table S2). Energy intake was higher in $\mathrm{HC}(2,780 \pm 1,169 \mathrm{kcal} / \mathrm{d})$ than in SS $(1,673 \pm 724 \mathrm{kcal} / \mathrm{d})$ and NASH $(1,892 \pm 656 \mathrm{kcal} / \mathrm{d})(\mathrm{p}<0.05)$. The macronutrient distribution (energy \% from protein, carbohydrates, fat, saturated, monounsaturated fat, PUFA) and physical activity were not different (Supplementary Table S3).

\section{Hepatic gene expression differed mainly between patients and $\mathrm{HC}$, with 22 genes clearly} distinguishing NASH from SS. 10,350 probes varied significantly among HC, SS, and NASH, with a reasonable, albeit not perfect separation of the samples into groups (Figure 1); 822 probes corresponding to 732 unique genes passed the 2-fold change filtering. Most differences were found between HC and NASH (556 genes), while 530 genes were differentially expressed between HC and SS; most genes were down-regulated compared with HC (NASH 56\%, SS $66 \%$ ). Genes shared by these two comparisons varied in the same direction, but with a different fold (Supplementary Tables S4a-c).

Twenty-two genes differed between NASH and SS (Table 2), including genes involved in FA desaturation (ACOT1), ether lipid metabolism (ENPP2), inflammatory pathways, detoxification, growth and development processes, and apoptosis (Supplementary Table S5). The highest foldchanges were seen for AKR1B10 (positive) and HLA-DRB5 (negative). The functional 
annotation analysis showed that in both SS and NASH the down-regulated genes compared to $\mathrm{HC}$ were enriched for terms related to cytokine signalling, apoptosis, response to exogenous or endogenous stimuli, cell migration, and angiogenesis (Supplementary Tables S6, S7). No enrichments were found for up-regulated genes or for DEG between NASH and SS. As several processes related to NAFLD are not considered as such in the existing databases, we constructed focused gene sets of specific interest, which were used for more detailed analysis in relation to FA composition. Most genes in the fibrosis, inflammatory response and oxidative stress sets were underrepresented in SS and NASH versus HC (Table 3). Thirty-three DEG belonged to the gene set for lipogenesis, one to beta-oxidation, and seven to long-chain and unsaturated FA metabolism. Except for ACOT1 none of these genes differed between SS and NASH.

A sensitivity analysis was performed for the DEG in these five sets as well as for those that differed between SS and NASH (in total 90 probes representing 78 unique genes). BMI group was a significant predictor (ANOVA F-test <0.05) only for five genes (DIO3OS, SPP1, PLAUR, GABRB3, SERPINE1) (Supplementary Table S8). After including BMI in the model, disease state was still a significant predictor for all genes, except for GABRB3, and the direction of the fold-changes observed within BMI groups was the same as in the original analysis. In line with the ANOVA results, PCA showed a clear separation between $\mathrm{HC}$ and patients for genes related to fibrosis, inflammatory response/oxidative stress, lipogenesis/beta-oxidation, and longchain/unsaturated FA metabolism, whereas for the 22 DEG between NASH and SS, the SS patients grouped with HC (Figure 2).

The extent of gene deregulation between NASH and SS is associated with disease severity. In the NAFLD patients (SS+NASH combined), most DEG between NASH and SS were strongly correlated with NAFLD activity score and liver enzymes, and to a lesser extent with HOMA-IR and BMI (Supplementary Table S9).

Correlations of PUFA with gene expression show different patterns in SS and NASH. Hepatic total FA profiles were compared only between SS and NASH. Hepatic n-3 and n-6 PUFA, especially the biologically active long-chain PUFA, i.e. eicosapentaenoic acid (EPA) + docosahexaneoic acid (DHA) and arachidonic acid (AA), and the AA precursor dihomo- $\gamma$ - 
linolenic acid were lower in NASH compared to SS (Table 4). This did not correspond to the erythrocyte FA profiles (Table 4) or the dietary PUFA intakes, which were similar among groups (Supplementary Table S3). Correlations between the expression levels of all DEG and PUFA (Supplementary Table 10) show different patterns depending on the group examined (SS, NASH, or both combined $=$ NAFLD) $($ Figure 3). Functional annotation analysis of genes correlated with EPA+DHA showed enrichment of the PPAR signaling pathway (5 genes, 21.7 fold enrichment, FDR 0.044) in NAFLD, and of cytokine-cytokine receptor interaction (8 genes, 11.1-fold enrichment, FDR 8.77E-04) in NASH. The same analysis for AA showed no significant results. Correlated genes were then filtered for the gene sets described above (Table 4). The results differed between SS, NASH, and both combined (NAFLD). When differences between SS and NASH were tested in ANCOVA models the interaction term for gene expression and diagnosis was significant for AA in six genes: CYP7A1, CXCR4 (p<0.01), JUB, MT1A, GGT1, and MTMR4 (p<0.05) (Supplementary Figure S2). The same was true for GGT1 in relation to EPA+DHA.

\section{Discussion}

Well-defined subjects with either healthy liver, SS or NASH showed distinct hepatic gene expression profiles. Only a small number of genes were differentially expressed between SS and $\mathrm{NASH}$, and they were significantly correlated with disease severity. In NASH, hepatic longchain PUFA were lower and their associations with gene expression were different than in SS.

Our results on global gene expression are in line with other publications showing dysregulation of lipogenesis $(4,11,21)$, apoptosis, and oxidative stress related genes (10) in NAFLD. Some observations like up-regulation of ACSL4 (4) and changes in the transcription factors PPAR- $\alpha$ and SREBP-1c (21) could not be reproduced. While others reported overexpression of genes related to wound healing and cell migration in NASH compared to SS and controls (11), these genes were down-regulated in both NASH and SS versus HC in our study. These discrepancies could be explained by differences in technology, bioinformatics, and the selected threshold of 2 fold up- or down-regulation. In addition, our participants' characteristics were different than in previous studies where all NAFLD patients were morbidly obese $(4,5,21)$ and various control groups were used $(4,5,11,20,21)$. We included a true $\mathrm{HC}$ group of living liver donors and our 
participants' mean BMI ranged from slightly overweight in HC to overall mildly obese in $\mathrm{NASH}$. This difference in BMI among the groups did not seem to influence our results, as demonstrated in our sensitivity analysis. However, the different liver biopsy protocols between NAFLD and HC (percutaneous liver biopsy versus hepatectomy) may have altered hepatic gene expression due to the effect of surgery (34). We could not perform percutaneous liver biopsies in $\mathrm{HC}$ prior to surgery due to ethical reasons.

Our study detected only 22 DEG between SS and NASH, which may be due to the relatively mild disease in the NASH group (median NAFLD activity score $=5 ; 47 \%$ of patients no or mild fibrosis; oxidative stress not detectable). Similar to others $(5,6,11)$ we found an overexpression of genes associated with cancer progression and proliferation in NASH versus SS, including AKR1B10, EEF1A2, SPP1 (osteopontin), and PEG10 (24). AKR1B10 was the most upregulated gene in NASH versus SS and HC, and the expression correlated with NAFLD activity score $(r=0.672, p<0.0001)$. This is in line with previous studies identifying this gene as a potential biomarker for $\mathrm{NASH}$ and progression to $\mathrm{HCC}(5,6,10,11)$. It is also interesting to note that AKR1B10 inhibitors were reported to have antitumor effects, supporting its role in cancer progression (35).

Due to the percutaneous liver biopsy technique performed in NAFLD, only very small samples were available for the FA composition. This prevented us to analyse all lipid sub-fractions. Therefore, only hepatic total lipid FA composition was measured. Because patients with NAFLD have higher proportions of triacylglycerols and lower phospholipids in the liver due to steatosis $(15,16)$, results from total lipid FA composition can be skewed if compared to HC, who have no steatosis. Since FA bound in these sub-fractions have distinct biological roles (16), they may also be of different significance for hepatic gene expression. Therefore we focused our FA analysis on SS and NASH, where steatosis is comparable (Table 1). We found lower n-3 and n-6 PUFA, especially AA and EPA+DHA, in NASH versus SS, but dietary intake according to food records and erythrocyte FA profiles (36) was similar between groups. The lower hepatic PUFA content was not associated with increased PUFA utilization through eicosanoids production or lipid peroxidation (15), as cyclooxygenase-2 (COX2 = PTGS2), a key enzyme in prostaglandin synthesis, was down-regulated similarly in NASH and SS compared to HC and, hepatic 
antioxidant power and lipid peroxidation were not different among the groups. Changes in FA metabolism, especially impaired conversion of essential FA to their long-chain PUFA product $(14,15)$, would be another explanation for lower AA and EPA+DHA in NASH. However, our results did not support this, as genes for elongases (ELOVL) and desaturases (FADS1, FADS2) involved in this conversion were not different between NASH and SS. In fact, FADS1 and FADS2 were up-regulated in NASH and to a smaller extent in SS versus HC as previously reported (20). This seems contradictory but can be explained if FADS1 and FADS2 are upregulated by low levels of long-chain PUFA, low protein expression or impaired catalytic activity of $\Delta 5$ and $\Delta 6$ desaturase. This would be consistent with some of the negative estimates of correlation coefficients found between EPA+DHA and FADS2 expression, which was significant in SS+NASH combined. Another reason could be genetic variations in the FADS1/2 gene cluster which were reported to influence transcription (37) and to be associated with lower indices for $\Delta 5 / \Delta 6$ desaturase activity (38). Based on animal and in vitro experiments, the dysregulation of PUFA desaturation may directly contribute to NASH development, and manipulation of the pathway could be a potential treatment target (20).

Another DEG of interest is PNPLA3, coding for adiponutrin, a triacylglycerol hydrolase. A genetic variant, PNPLA $3^{\mathrm{I1} 48 \mathrm{M}}$, predisposes to steatosis, fibrosis, and progression to HCC (39), especially in obesity (40). PNPLA $3^{\mathrm{I} 148 \mathrm{M}}$ was reported to increase hepatic triacylglycerol content and change hepatic FA composition, reducing n-6 PUFA (39). The effects of PNPLA ${ }^{\text {I148M }}$ can be modulated by a high n-6/n-3 PUFA ratio in the diet and can contribute to NAFLD in obese youth carrying the risk allele (40). A PUFA-gene interaction was also observed in a large epidemiological study, where a significant association between PNPLA3 ${ }^{\mathrm{I1} 48 \mathrm{M}}$ and plasma triacylglycerols was found only in overweight participants having a low ratio of $n-6 / n-3$ PUFA in their diet (41). In our study, genotyping was not available, but PNPLA3 was up-regulated in $\mathrm{NASH}(+2.38)$ and SS (+1.7; p<0.05) versus HC, and expression levels were negatively correlated with AA in NAFLD (SS+NASH), supporting an interrelation between PNPLA3, n-6 PUFA, and NAFLD pathogenesis. Genotyping for the PNPLA3 ${ }^{\mathrm{I} 148 \mathrm{M}}$ allele may be of interest in future studies as it can predispose to NAFLD and modulate the response to PUFA supplementation. 
Other genes had different associations with PUFA in NASH compared with SS. For example, CYP7A1, crucial for bile acid synthesis and cholesterol catabolism (24), was positively correlated with AA in NASH but negatively in SS ( $\mathrm{p}=0.055)$. These different associations between genes related to lipid metabolism and PUFA content in SS versus NASH could explain some of the conflicting results seen in n-3 PUFA supplementation studies where steatosis improved on imaging (no distinction between SS and NASH (19), while no effect was seen on liver biopsy proven NASH (42).

The strengths of this study include the true HC group confirmed by histology and the measurements of both gene expression and FA in the same liver samples. Potential limitations include the use of tissue from hepatectomy which may have influenced the gene expression in HC (34) and the small amount of tissue available in NAFLD, which did not allow for a more detailed lipid analysis. Future studies could separate different cell types from the whole tissue, as the cellular composition influences gene expression (43) and perform proteomic analysis to examine gene transcription (5). Furthermore, the cross-sectional nature of our study does not allow us to establish causal relationships, especially since hepatic gene expression and FA composition are subject to reciprocal regulation. Further studies are needed to clarify this relationship and determine which changes in hepatic gene expression can predict the development of NASH and disease progression and which genes respond to specific PUFA supplementation. Due to the different relationships between genes and PUFA in SS and NASH, these two groups should be analyzed separately.

\section{Conclusion}

Hepatic gene expression differs between NAFLD and HC, including genes that may influence FA composition. A small number of DEG distinguishes NASH from SS, but more of them relate to HCC than to lipid metabolism. Hepatic long-chain n-3 and n-6 PUFA, especially EPA, DHA, and AA are lower in NASH compare with SS. This may be due to dysregulation of FADS1/2 and PNPLA3 as PUFA intake and oxidative stress are similar between groups. The associations between genes and PUFA are different in NASH compared with SS. As a result, responses to specific PUFA supplementation may be different in NASH versus SS. In order to establish causal relationships between PUFA and gene expression, intervention studies with n-3 and/or n-6 PUFA 
are required in well characterized patients. In addition, genotyping for PNPLA3 may be considered.

\section{Acknowledgement}

We thank the Princess Margaret Genomics Centre, Toronto, Canada (www.pmgenomics.ca) for the analysis of hepatic gene expression; Seham Noureldin and Julia Bonengel for recruitment; Nita Prayitno, Lyn Hillyer, Natasha Singh, Hannah Da Silva and Amel Taibi for laboratory analyses; AnaLaura Guzman for food record entry; and Laura Bosco for literature research. 


\section{References}

1. Dowman JK, Tomlinson JW, Newsome PN. Pathogenesis of non-alcoholic fatty liver disease. Q J Med 2010;103:71-83.

2. Schuppan D, Schattenberg JM. Non-alcoholic steatohepatitis: pathogenesis and novel therapeutic approaches. J Gastroenterol Hepatol 2013;28 Suppl 1:68-76.

3. LaBrecque D, Abbas Z, Anania F, Ferenci P, Ghafoor Khan A, Goh K-L, et al. World Gastroenterology Organisation Global Guidelines. Nonalcoholic fatty liver disease and nonalcoholic steatohepatitis: World Gastroenterology Organisation 2012.

4. Younossi ZM, Gorreta F, Ong JP, Schlauch K, Giacco LD, Elariny H, et al. Hepatic gene expression in patients with obesity-related non-alcoholic steatohepatitis. Liver Int 2005;25:76071.

5. Younossi ZM, Baranova A, Ziegler K, Del Giacco L, Schlauch K, Born TL, et al. A genomic and proteomic study of the spectrum of nonalcoholic fatty liver disease. Hepatology 2005;42:665-74.

6. Lake AD, Novak P, Fisher CD, Jackson JP, Hardwick RN, Billheimer DD, et al. Analysis of global and absorption, distribution, metabolism, and elimination gene expression in the progressive stages of human nonalcoholic fatty liver disease. Drug Metab Dispos 2011;39:195460.

7. Baker SS, Baker RD, Liu W, Nowak NJ, Zhu L. Role of alcohol metabolism in non-alcoholic steatohepatitis. PLoS One 2010;5:e9570.

8. Zhang Y, Baker SS, Baker RD, Zhu R, Zhu L. Systematic analysis of the gene expression in the livers of nonalcoholic steatohepatitis: implications on potential biomarkers and molecular pathological mechanism. PLoS One 2012;7:e51131.

9. Moylan CA, Pang H, Dellinger A, Suzuki A, Garrett ME, Guy CD, et al. Hepatic gene expression profiles differentiate presymptomatic patients with mild versus severe nonalcoholic fatty liver disease. Hepatology 2014;59:471-82.

10. Yoneda M, Endo H, Mawatari H, Nozaki Y, Fujita K, Akiyama T, et al. Gene expression profiling of non-alcoholic steatohepatitis using gene set enrichment analysis. Hepatol Res 2008;38:1204-12.

11. Starmann J, Falth M, Spindelbock W, Lanz KL, Lackner C, Zatloukal K, et al. Gene expression profiling unravels cancer-related hepatic molecular signatures in steatohepatitis but 
not in steatosis. PLoS One 2012;7:e46584.

12. Scorletti E, Byrne CD. Omega-3 fatty acids, hepatic lipid metabolism, and nonalcoholic fatty liver disease. Annu Rev Nutr 2013;33:231-48.

13. Rudkowska I, Paradis AM, Thifault E, Julien P, Tchernof A, Couture P, et al. Transcriptomic and metabolomic signatures of an n-3 polyunsaturated fatty acids supplementation in a normolipidemic/normocholesterolemic Caucasian population. J Nutr Biochem 2013;24:54-61. 14. Allard JP, Aghdassi E, Mohammed S, Raman M, Avand G, Arendt BM, et al. Nutritional assessment and hepatic fatty acid composition in non-alcoholic fatty liver disease (NAFLD): a cross-sectional study. J Hepatol 2008;48:300-7.

15. Araya J, Rodrigo R, Videla LA, Thielemann L, Orellana M, Pettinelli P, et al. Increase in long-chain polyunsaturated fatty acid n - 6/n - 3 ratio in relation to hepatic steatosis in patients with non-alcoholic fatty liver disease. Clin Sci (Lond) 2004;106:635-43.

16. Puri P, Baillie RA, Wiest MM, Mirshahi F, Choudhury J, Cheung O, et al. A lipidomic analysis of nonalcoholic fatty liver disease. Hepatology 2007;46:1081-90.

17. Zelber-Sagi S, Nitzan-Kaluski D, Goldsmith R, Webb M, Blendis L, Halpern Z, et al. Long term nutritional intake and the risk for non-alcoholic fatty liver disease (NAFLD): a population based study. J Hepatol 2007;47:711-7.

18. Da Silva HE, Arendt BM, Noureldin SA, Therapondos G, Guindi M, Allard JP. A crosssectional study assessing dietary intake and physical activity in Canadian patients with nonalcoholic fatty liver disease vs healthy controls. J Acad Nutr Diet 2014;114:1181-94. 19. Parker HM, Johnson NA, Burdon CA, Cohn JS, O'Connor HT, George J. Omega-3 supplementation and non-alcoholic fatty liver disease: a systematic review and meta-analysis. J Hepatol 2012;56:944-51.

20. Lopez-Vicario C, Gonzalez-Periz A, Rius B, Moran-Salvador E, Garcia-Alonso V, Lozano JJ, et al. Molecular interplay between delta5/delta6 desaturases and long-chain fatty acids in the pathogenesis of non-alcoholic steatohepatitis. Gut 2014;63:344-55.

21. Pettinelli P, Del Pozo T, Araya J, Rodrigo R, Araya AV, Smok G, et al. Enhancement in liver SREBP-1c/PPAR-alpha ratio and steatosis in obese patients: correlations with insulin resistance and n-3 long-chain polyunsaturated fatty acid depletion. Biochim Biophys Acta 2009;1792:10806.

22. Brunt EM, Janney CG, Di Bisceglie AM, Neuschwander-Tetri BA, Bacon BR. Nonalcoholic 
steatohepatitis: a proposal for grading and staging the histological lesions. Am J Gastroenterol 1999;94:2467-74.

23. Kleiner DE, Brunt EM, Van Natta M, Behling C, Contos MJ, Cummings OW, et al. Design and validation of a histological scoring system for nonalcoholic fatty liver disease. Hepatology 2005;41:1313-21.

24. Pruitt K, Brown G, Tatusova T, Maglott D. The Reference Sequence (RefSeq) Project. The NCBI handbook [Internet]. Bethesda, MD, USA: National Library of Medicine (US), National Center for Biotechnology Information, 2002.

25. Du P, Kibbe WA, Lin SM. lumi: a pipeline for processing Illumina microarray. Bioinformatics 2008;24:1547-8.

26. Huang DW, Sherman BT, Lempicki RA. Systematic and integrative analysis of large gene lists using DAVID Bioinformatics Resources. Nature Protocols 2009;4:44-57.

27. Huang DW, Sherman BT, Lempicki RA. Bioinformatics enrichment tools: paths toward the comprehensive functional analysis of large gene lists. Nucleic Acids Res 2009;37:1-13.

28. Lau DT, Luxon BA, Xiao SY, Beard MR, Lemon SM. Intrahepatic gene expression profiles and alpha-smooth muscle actin patterns in hepatitis $\mathrm{C}$ virus induced fibrosis. Hepatology 2005;42:273-81.

29. Yauk CL, Berndt ML, Williams A, Douglas GR. Comprehensive comparison of six microarray technologies. Nucleic Acids Res 2004;32:e124.

30. Folch J, Lees M, Sloane Stanley GH. A simple method for the isolation and purification of total lipids from animal tissues. J Biol Chem 1957;226:497-509.

31. Ma DW, Ngo V, Huot PS, Kang JX. N-3 polyunsaturated fatty acids endogenously synthesized in fat-1 mice are enriched in the mammary gland. Lipids 2006;41:35-9.

32. Matthews DR, Hosker JP, Rudenski AS, Naylor BA, Treacher DF, Turner RC. Homeostasis model assessment: insulin resistance and beta-cell function from fasting plasma glucose and insulin concentrations in man. Diabetologia 1985;28:412-9.

33. Pan XR, Li GW, Hu YH, Wang JX, Yang WY, An ZX, et al. Effects of diet and exercise in preventing NIDDM in people with impaired glucose tolerance. The Da Qing IGT and Diabetes Study. Diabetes Care 1997;20:537-44.

34. Asselah T, Bieche I, Laurendeau I, Martinot-Peignoux M, Paradis V, Vidaud D, et al. Significant gene expression differences in histologically "normal" liver biopsies: implications for 
control tissue. Hepatology 2008;48:953-62.

35. Liu J, Wen G, Cao D. Aldo-keto reductase family 1 member B1 inhibitors: old drugs with new perspectives. Recent Pat Anticancer Drug Discov 2009;4:246-53.

36. Katan MB, Deslypere JP, van Birgelen AP, Penders M, Zegwaard M. Kinetics of the incorporation of dietary fatty acids into serum cholesteryl esters, erythrocyte membranes, and adipose tissue: an 18- month controlled study. J Lipid Res 1997;38:2012-22.

37. Lattka E, Eggers S, Moeller G, Heim K, Weber M, Mehta D, et al. A common FADS2 promoter polymorphism increases promoter activity and facilitates binding of transcription factor ELK1. J Lipid Res 2010;51:182-91.

38. Merino DM, Johnston H, Clarke S, Roke K, Nielsen D, Badawi A, et al. Polymorphisms in FADS1 and FADS2 alter desaturase activity in young Caucasian and Asian adults. Mol Genet Metab 2011;103:171-8.

39. Peter A, Kovarova M, Nadalin S, Cermak T, Konigsrainer A, Machicao F, et al. PNPLA3 variant I148M is associated with altered hepatic lipid composition in humans. Diabetologia 2014;57:2103-7.

40. Santoro N, Savoye M, Kim G, Marotto K, Shaw MM, Pierpont B, et al. Hepatic fat accumulation is modulated by the interaction between the rs 738409 variant in the PNPLA3 gene and the dietary omega6/omega3 PUFA intake. PLoS One 2012;7:e37827.

41. Stojkovic IA, Ericson U, Rukh G, Riddestrale M, Romeo S, Orho-Melander M. The PNPLA3 Ile148Met interacts with overweight and dietary intakes on fasting triglyceride levels. Genes Nutr 2014;9:388.

42. Sanyal AJ, Abdelmalek MF, Suzuki A, Cummings OW, Chojkier M. No significant effects of ethyl-eicosapentanoic acid on histologic features of nonalcoholic steatohepatitis in a phase 2 trial. Gastroenterology 2014;147:377-84 e1.

43. Zuckerman NS, Noam Y, Goldsmith AJ, Lee PP. A self-directed method for cell-type identification and separation of gene expression microarrays. PLoS Comput Biol 2013;9:e1003189. 
Table 1: Demography, clinical data, and oxidative stress measurements

\begin{tabular}{|c|c|c|c|c|c|c|}
\hline & $\mathbf{n}$ & $\mathrm{HC}$ & $\mathbf{n}$ & SS & $\mathbf{n}$ & NASH \\
\hline Age (years) & 24 & $37.2 \pm 10.8$ & 20 & $44.7 \pm 9.1$ & 19 & $43.5 \pm 12.7$ \\
\hline Male sex $(\%(n / n))$ & 24 & $45.9 \%(11 / 24)$ & 20 & $70.0(14 / 20)$ & 19 & $47.4 \%(9 / 19)$ \\
\hline $\begin{array}{l}\text { Ethnicity }(\%(\mathbf{n} / \mathbf{n})) \\
\text { Caucasian } \\
\text { Asian } \\
\text { other }\end{array}$ & 20 & $\begin{array}{c}85.0 \%(17 / 20) \\
10.0 \%(2 / 20) \\
5.0 \%(1 / 20)\end{array}$ & 13 & $\begin{array}{l}53.9 \%(7 / 13) \\
30.8 \%(4 / 13) \\
15.4 \%(2 / 13)\end{array}$ & 16 & $\begin{array}{c}68.8 \%(11 / 16) \\
25.0 \%(4 / 16) \\
6.3 \%(1 / 16)\end{array}$ \\
\hline BMI $\left(\mathrm{kg} / \mathrm{m}^{2}\right)$ & 24 & $26.1(5.6)$ & 19 & $28.6(4.9)^{\mathrm{a}}$ & 18 & $31.9(3.8)^{A, D}$ \\
\hline Waist & 22 & $88.95 \pm 10.96$ & 19 & $99.73 \pm 9.97$ & 16 & $104 \pm 10.4^{a}$ \\
\hline Smoking (\% (n/n)) & 24 & $0.0 \%(0 / 24)$ & 20 & $10.0 \%(2 / 20)$ & 19 & $21.1 \%(4 / 19)^{a}$ \\
\hline Cigarettes/day & 24 & $0.0(0.0)$ & 20 & $0.0(0.0)$ & 19 & $0.0(0.0)$ \\
\hline Alcohol & 24 & $0.00(2.80)$ & 20 & $0.00(1.93)$ & 19 & $1.00(4.00)$ \\
\hline $\begin{array}{l}\text { Steatosis (\% of } \\
\text { hepatocytes) }\end{array}$ & 17 & $0.0(0.0)$ & 20 & $35.0(40.0)^{\mathrm{A}}$ & 19 & $40.0(45.0)^{\mathrm{A}}$ \\
\hline $\begin{array}{l}\text { Steatosis grading }(\% \text { of } \\
\text { patients }(\mathrm{n})) \\
0 / 1 / 2 / 3\end{array}$ & 17 & $\begin{array}{l}100 / 0 / 0 / 0 \\
(17 / 0 / 0 / 0)\end{array}$ & 20 & $\begin{array}{c}0 / 50.0 / 35.0 / 15.0 \\
(0 / 10 / 7 / 3)\end{array}$ & 19 & $\begin{array}{c}0 / 31.6 / 36.8 / 31.6 \\
(0 / 6 / 7 / 6)\end{array}$ \\
\hline $\begin{array}{l}\text { Fibrosis stage } \\
\text { (\% of patients (n)) } \\
0 / 1 / 2 / 3 / 4\end{array}$ & 16 & $\begin{array}{c}62.5 / 37.5 / 0 / 0 / 0 \\
(10 / 6 / 0 / 0 / 0)\end{array}$ & 20 & $\begin{array}{l}85 / 15 / 0 / 0 / 0 \\
(17 / 3 / 0 / 0 / 0)\end{array}$ & 19 & $\begin{array}{c}21 / 26 / 11 / 21 / 21 \\
(4 / 5 / 2 / 4 / 4)\end{array}$ \\
\hline NAS Score $(0-8)$ & 7 & $0.00(0.00)$ & 19 & $2.00(1.00)^{\mathrm{A}}$ & 19 & $5.00(2.00)^{\mathrm{A}, \mathrm{B}}$ \\
\hline $\begin{array}{l}\text { Liver AOP ( } \mu \mathrm{mol} \text { uric } \\
\text { acid equivalents / } \mathrm{g} \\
\text { tissue)) }\end{array}$ & 24 & $36.8(25.8)$ & 20 & $32.3(31.1)$ & 18 & $30.0(31.9)$ \\
\hline $\begin{array}{l}\text { Liver LPO ( } \mu \mathrm{mol} \\
\text { malondialdehyde / g } \\
\text { tissue }\end{array}$ & 24 & $0.08(0.20)$ & 20 & $0.20(0.43)$ & 17 & $0.19(1.18)$ \\
\hline
\end{tabular}

HC: healthy controls, SS: simple steatosis, NASH: nonalcoholic steatohepatitis, NAS: nonalcoholic fatty liver activity score, AOP: antioxidant power; LPO: lipid peroxidation Values given are mean $\pm S D$, median (interquartile range) or $\%$ of valid cases.

Superscript letters show statistically significant difference from healthy controls $(a, A)$ and from $S S(b, B)$. a,b: $p<0.05$, A,B: $p<0.01$. ANOVA with Tukey's post-hoc test was used for normally distributed data, Wilcoxon test for data with skewed distribution, and Fisher's exact test for categorical variables. Steatosis grading according to Brunt et al. (22). 0: $<5 \%$ of hepatocytes involved, 1: 5-33\%, 2: 33-66\%, 3:3 (>66\%). NAS according to Kleiner et al. (23). 
Table 2: Differentially expressed genes between patients with simple steatosis and nonalcoholic steatohepatitis

\begin{tabular}{|c|c|c|c|c|c|c|}
\hline \multirow{2}{*}{$\begin{array}{r}\text { Entrez } \\
\text { Gene } \\
\text { ID }\end{array}$} & \multirow[b]{2}{*}{$\begin{array}{l}\text { Gene } \\
\text { Symbol }\end{array}$} & \multicolumn{3}{|c|}{ Fold-change } & \multirow[b]{2}{*}{ q-value } & \multirow[b]{2}{*}{ Definition } \\
\hline & & $\begin{array}{l}\text { NASH } \\
\text { vs SS }\end{array}$ & $\begin{array}{l}\text { NASH } \\
\text { vs HC }\end{array}$ & $\begin{array}{c}\text { SS vs } \\
\text { HC }\end{array}$ & & \\
\hline 57016 & AKR1B10 & 6.20 & 9.95 & -- & $4.84 \mathrm{E}-11$ & $\begin{array}{l}\text { aldo-keto reductase family } 1, \text { member B10 } \\
\text { (aldose reductase) }\end{array}$ \\
\hline 1917 & EEF1A2 & 3.40 & 4.88 & -- & $8.49 \mathrm{E}-08$ & $\begin{array}{l}\text { eukaryotic translation elongation factor } 1 \\
\text { alpha } 2\end{array}$ \\
\hline 641371 & ACOT1 & 2.99 & -- & -2.73 & $3.80 \mathrm{E}-02$ & acyl-CoA thioesterase 1 \\
\hline 343071 & PRAMEF10 & 2.57 & -- & -- & 7.01E-03 & PRAME family member 10 \\
\hline 80201 & HKDC1 & 2.49 & -- & -- & $1.56 \mathrm{E}-03$ & hexokinase domain containing 1 \\
\hline 11075 & STMN2 & 2.45 & 2.05 & -- & $1.74 \mathrm{E}-03$ & stathmin-like 2 \\
\hline 2562 & GABRB3 & 2.43 & -- & -- & 3.90E-04 & $\begin{array}{l}\text { gamma-aminobutyric acid A receptor, beta } 3 \text {, } \\
\text { transcript variant } 1\end{array}$ \\
\hline 6696 & SPP1 & 2.36 & -- & -- & $5.51 \mathrm{E}-04$ & $\begin{array}{l}\text { secreted phosphoprotein 1, transcript variant } \\
1\end{array}$ \\
\hline 10537 & UBD & 2.26 & 2.23 & -- & 2.15E-05 & ubiquitin D \\
\hline 23089 & PEG10 & 2.20 & 4.43 & 2.01 & $7.75 \mathrm{E}-11$ & paternally expressed 10 , transcript variant 1 \\
\hline 2326 & FM01 & 2.19 & 5.07 & 2.31 & $3.29 E-13$ & flavin containing monooxygenase 1 \\
\hline 5168 & ENPP2 & 2.10 & -- & -- & $6.87 \mathrm{E}-05$ & $\begin{array}{l}\text { ectonucleotide } \\
\text { pyrophosphatase/phosphodiesterase } 2 \text {, } \\
\text { transcript variant } 2\end{array}$ \\
\hline 51473 & DCDC2 & 2.07 & 2.08 & -- & 2.35E-03 & doublecortin domain containing 2 \\
\hline 2191 & FAP & 2.04 & -- & -- & 1.16E-03 & fibroblast activation protein, alpha \\
\hline 302 & ANXA2 & 2.02 & -- & -2.19 & 2.79E-05 & annexin $\mathrm{A} 2$, transcript variant 2 \\
\hline 677818 & SNORA36B & -2.06 & -2.22 & -- & $2.60 \mathrm{E}-02$ & $\begin{array}{l}\text { small nucleolar RNA, H/ACA box 36B, small } \\
\text { nucleolar RNA }\end{array}$ \\
\hline 4489 & MT1A & -2.18 & -5.06 & -2.32 & 4.55E-08 & metallothionein $1 \mathrm{~A}$ \\
\hline 692225 & SNORD94 & -2.25 & -- & 2.06 & $1.20 \mathrm{E}-02$ & $\begin{array}{l}\text { small nucleolar RNA, C/D box 94, small } \\
\text { nucleolar RNA }\end{array}$ \\
\hline 4099 & MAG & -2.46 & -- & -- & 2.27E-03 & $\begin{array}{l}\text { myelin associated glycoprotein, transcript } \\
\text { variant } 2\end{array}$ \\
\hline 4490 & MT1B & -2.52 & -3.26 & -- & 1.24E-03 & metallothionein 1B \\
\hline 64150 & DIO30S & -2.53 & -3.28 & -- & $1.82 E-06$ & $\begin{array}{l}\text { DIO3 opposite strand (non-protein coding), } \\
\text { non-coding RNA }\end{array}$ \\
\hline 3127 & HLA-DRB5 & -4.43 & -- & -- & $3.59 \mathrm{E}-02$ & $\begin{array}{l}\text { major histocompatibility complex, class II, DR } \\
\text { beta } 5\end{array}$ \\
\hline
\end{tabular}

HC: healthy controls, SS: simple steatosis, NASH: nonalcoholic steatohepatitis,

Gene expression levels are given as fold-changes between two groups. --: not significant in two-group comparison (post-hoc $p$-value $\geq 0.05$ ) and/or less than 2 -fold up- or down-regulation. The q-value is the Benjamini-Hochberg corrected $p$-value. 
Table 3: Genes related to biological processes relevant for NAFLD that are differentially expressed among healthy controls and patients with simple steatosis or nonalcoholic steatohepatitis

\begin{tabular}{|c|c|c|c|c|c|}
\hline \multirow{2}{*}{$\begin{array}{l}\text { Entrez } \\
\text { Gene } \\
\text { ID }\end{array}$} & \multirow[b]{2}{*}{ Symbol } & \multicolumn{2}{|c|}{ Fold-change } & \multirow[b]{2}{*}{ q-value } & \multirow[b]{2}{*}{ Definition } \\
\hline & & $\begin{array}{l}\text { NASH vs } \\
\text { HC }\end{array}$ & $\begin{array}{l}\text { SS vs } \\
\text { HC }\end{array}$ & & \\
\hline \multicolumn{6}{|c|}{ Fibrosis } \\
\hline 3569 & IL6 & -8.96 & -7.25 & $7.64 \mathrm{E}-11$ & interleukin 6 (interferon, beta 2) \\
\hline 4609 & MYC & -7.43 & -8.14 & $4.96 \mathrm{E}-17$ & $\begin{array}{l}\text { v-myc myelocytomatosis viral oncogene homolog } \\
\text { (avian) }\end{array}$ \\
\hline 7057 & THBS1 & -3.50 & -4.46 & $1.10 \mathrm{E}-15$ & thrombospondin 1 \\
\hline 7043 & TGFB3 & -3.42 & -3.91 & $1.35 \mathrm{E}-08$ & transforming growth factor, beta 3 ) \\
\hline 6347 & CCL2 & -3.23 & -3.57 & $6.12 \mathrm{E}-13$ & chemokine ( $\mathrm{C}-\mathrm{C}$ motif) ligand 2 \\
\hline 3553 & IL1B & -3.17 & -3.57 & 4.71E-09 & interleukin 1, beta \\
\hline 5054 & SERPINE1 & -2.86 & -3.28 & $6.16 \mathrm{E}-09$ & $\begin{array}{l}\text { serpin peptidase inhibitor, clade } \mathrm{E} \text { (nexin, } \\
\text { plasminogen activator inhibitor type 1), member } 1\end{array}$ \\
\hline 3586 & IL10 & -2.29 & -- & $2.46 \mathrm{E}-08$ & interleukin 10 \\
\hline 3725 & JUN & -2.28 & -3.04 & $1.61 \mathrm{E}-13$ & jun oncogene \\
\hline 6348 & CCL3 & -2.26 & -2.00 & $1.77 \mathrm{E}-04$ & chemokine ( $\mathrm{C}-\mathrm{C}$ motif) ligand 3 \\
\hline 5265 & SERPINA1 & -2.05 & -2.40 & 3.50E-07 & $\begin{array}{l}\text { serpin peptidase inhibitor, clade } \mathrm{A} \text { (alpha-1 } \\
\text { antiproteinase, antitrypsin), member } 1 \text {, transcript } \\
\text { variant } 2\end{array}$ \\
\hline 7852 & CXCR4 & -2.00 & -2.59 & $1.82 \mathrm{E}-06$ & $\begin{array}{l}\text { chemokine (C-X-C motif) receptor } 4 \text {, transcript } \\
\text { variant } 2\end{array}$ \\
\hline 4318 & MMP9 & -- & -2.31 & $1.21 \mathrm{E}-04$ & $\begin{array}{l}\text { matrix metallopeptidase } 9 \text { (gelatinase } \mathrm{B}, 92 \mathrm{kDa} \\
\text { gelatinase, } 92 \mathrm{kDa} \text { type IV collagenase) }\end{array}$ \\
\hline \multicolumn{6}{|c|}{ Chronic inflammatory response } \\
\hline 7057 & THBS1 & -3.50 & -4.46 & 1.10E-15 & thrombospondin 1 \\
\hline 3557 & IL1RN & -3.58 & -4.44 & 4.53E-09 & $\begin{array}{l}\text { interleukin } 1 \text { receptor antagonist, transcript variant } \\
1\end{array}$ \\
\hline 3557 & IL1RN & -3.00 & -2.90 & $6.30 \mathrm{E}-08$ & $\begin{array}{l}\text { interleukin } 1 \text { receptor antagonist, transcript variant } \\
4\end{array}$ \\
\hline 6279 & S100A8 & -2.98 & -2.26 & 5.99E-06 & S100 calcium binding protein A8 \\
\hline 3586 & IL10 & -2.29 & -- & $2.46 \mathrm{E}-08$ & interleukin 10 \\
\hline \multicolumn{6}{|c|}{ Cellular response to oxidative stress } \\
\hline 3569 & IL6 & -8.96 & -7.25 & $7.64 \mathrm{E}-11$ & interleukin 6 (interferon, beta 2) \\
\hline 2353 & FOS & -7.39 & -6.82 & 4.09E-14 & $\begin{array}{l}\text { v-fos FBJ murine osteosarcoma viral oncogene } \\
\text { homolog }\end{array}$ \\
\hline 9314 & KLF4 & -3.66 & -3.24 & 3.77E-09 & Kruppel-like factor 4 (gut) \\
\hline 4929 & NR4A2 & -3.35 & -3.06 & 1.99E-09 & $\begin{array}{l}\text { nuclear receptor subfamily } 4 \text {, group } A \text {, member } 2 \text {, } \\
\text { transcript variant } 1\end{array}$ \\
\hline 2308 & F0X01 & -2.18 & -2.02 & $6.46 \mathrm{E}-10$ & forkhead box 01 \\
\hline 983 & CDC2 & 2.09 & -- & $1.30 \mathrm{E}-10$ & $\begin{array}{l}\text { cell division cycle 2, G1 to S and G2 to M, transcript } \\
\text { variant } 1\end{array}$ \\
\hline 3934 & LCN2 & -- & -2.13 & $2.15 \mathrm{E}-02$ & lipocalin 2 \\
\hline
\end{tabular}

Arendt et al. Hepatology Volume 61, Issue 5, May 2015, Pages 1565-1578

Published version at http://onlinelibrary.wiley.com/doi/10.1002/hep.27695/full 


\begin{tabular}{|c|c|c|c|c|c|}
\hline 5311 & PKD2 & -- & 2.07 & 2.46E-05 & polycystic kidney disease 2 (autosomal dominant) \\
\hline \multicolumn{6}{|c|}{ Lipogenesis } \\
\hline 150094 & SIK1 & -5.29 & -5.54 & $5.06 \mathrm{E}-12$ & salt-inducible kinase 1 \\
\hline 5743 & PTGS2 & -4.50 & -3.79 & $2.54 \mathrm{E}-11$ & $\begin{array}{l}\text { prostaglandin-endoperoxide synthase } 2 \\
\text { (prostaglandin G/H synthase and cyclooxygenase) }\end{array}$ \\
\hline 3491 & CYR61 & -3.54 & -4.69 & 2.23E-14 & cysteine-rich, angiogenic inducer, 61 \\
\hline 84803 & AGPAT9 & -3.17 & -2.24 & $5.95 \mathrm{E}-17$ & 1-acylglycerol-3-phosphate O-acyltransferase 9 \\
\hline 552 & AVPR1A & -3.09 & -3.32 & $6.75 \mathrm{E}-07$ & arginine vasopressin receptor $1 \mathrm{~A}$ \\
\hline 6279 & S100A8 & -2.98 & -2.26 & $5.99 \mathrm{E}-06$ & S100 calcium binding protein $A 8$ \\
\hline 5329 & PLAUR & -2.97 & -3.72 & $9.19 \mathrm{E}-10$ & $\begin{array}{l}\text { plasminogen activator, urokinase receptor, } \\
\text { transcript variant } 2\end{array}$ \\
\hline 55500 & ETNK1 & -2.58 & -2.18 & $1.78 \mathrm{E}-10$ & ethanolamine kinase 1 , transcript variant 2 \\
\hline 5329 & PLAUR & -2.44 & -2.34 & $1.46 \mathrm{E}-12$ & $\begin{array}{l}\text { plasminogen activator, urokinase receptor, } \\
\text { transcript variant } 1\end{array}$ \\
\hline 9023 & $\mathrm{CH} 25 \mathrm{H}$ & -2.05 & -2.14 & $9.81 \mathrm{E}-05$ & cholesterol 25-hydroxylase \\
\hline 220 & ALDH1A3 & -2.03 & -2.06 & 1.47E-04 & aldehyde dehydrogenase 1 family, member A3 \\
\hline 23600 & AMACR & 2.00 & -- & 3.26E-06 & $\begin{array}{l}\text { alpha-methylacyl-CoA racemase, transcript variant } \\
1\end{array}$ \\
\hline 2678 & GGT1 & 2.01 & -- & 1.67E-06 & gamma-glutamyltransferase 1 , transcript variant 1 \\
\hline 116285 & ACSM1 & 2.03 & -- & 8.62E-04 & $\begin{array}{l}\text { acyl-CoA synthetase medium-chain family member } \\
1\end{array}$ \\
\hline 9110 & MTMR4 & 2.05 & 2.16 & 4.60E-09 & myotubularin related protein 4 \\
\hline 3357 & HTR2B & 2.07 & -- & $1.08 \mathrm{E}-05$ & 5-hydroxytryptamine (serotonin) receptor 2B \\
\hline 84962 & JUB & 2.10 & -- & 2.57E-06 & $\begin{array}{l}\text { jub, ajuba homolog (Xenopus laevis), transcript } \\
\text { variant } 1\end{array}$ \\
\hline 23600 & AMACR & 2.13 & -- & 1.33E-06 & $\begin{array}{l}\text { alpha-methylacyl-CoA racemase, transcript variant } \\
2\end{array}$ \\
\hline 3172 & HNF4A & 2.20 & -- & 8.00E-05 & $\begin{array}{l}\text { hepatocyte nuclear factor 4, alpha, transcript } \\
\text { variant } 3\end{array}$ \\
\hline 55304 & SPTLC3 & 2.37 & -- & 3.65E-08 & $\begin{array}{l}\text { serine palmitoyltransferase, long chain base } \\
\text { subunit } 3\end{array}$ \\
\hline 80339 & PNPLA3 & 2.38 & -- & 2.27E-06 & patatin-like phospholipase domain containing 3 \\
\hline 672 & BRCA1 & 2.39 & 2.43 & $1.50 \mathrm{E}-07$ & $\begin{array}{l}\text { breast cancer 1, early onset, transcript variant } \\
\text { BRCA1-delta14-17 }\end{array}$ \\
\hline 672 & BRCA1 & 2.45 & 2.46 & 4.41E-07 & $\begin{array}{l}\text { breast cancer } 1 \text {, early onset, transcript variant } \\
\text { BRCA1-delta11b }\end{array}$ \\
\hline 56848 & SPHK2 & 2.46 & 2.18 & $1.00 \mathrm{E}-05$ & sphingosine kinase 2 \\
\hline 3992 & FADS1 & 2.49 & 2.09 & 9.61E-06 & fatty acid desaturase 1 \\
\hline 80168 & MOGAT2 & 2.57 & 2.65 & 4.14E-10 & monoacylglycerol O-acyltransferase 2 \\
\hline 84962 & JUB & 2.72 & -- & $1.21 \mathrm{E}-08$ & $\begin{array}{l}\text { jub, ajuba homolog (Xenopus laevis), transcript } \\
\text { variant } 2\end{array}$ \\
\hline 9415 & FADS2 & 2.81 & -- & 1.07E-04 & fatty acid desaturase 2 \\
\hline 57678 & GPAM & 2.82 & 2.40 & $3.46 \mathrm{E}-07$ & $\begin{array}{l}\text { glycerol-3-phosphate acyltransferase, } \\
\text { mitochondrial, nuclear gene encoding mitochondrial } \\
\text { protein }\end{array}$ \\
\hline 2645 & GCK & 4.35 & 4.57 & 1.83E-06 & glucokinase (hexokinase 4), transcript variant 3 \\
\hline
\end{tabular}

Arendt et al. Hepatology Volume 61, Issue 5, May 2015, Pages 1565-1578 Post-print version

Published version at http://onlinelibrary.wiley.com/doi/10.1002/hep.27695/full 


\begin{tabular}{|c|c|c|c|c|c|}
\hline 1581 & CYP7A1 & 8.34 & 6.53 & $3.59 \mathrm{E}-12$ & $\begin{array}{l}\text { cytochrome P450, family } 7 \text {, subfamily A, } \\
\text { polypeptide } 1\end{array}$ \\
\hline 5359 & PLSCR1 & -- & -2.15 & 7.23E-05 & phospholipid scramblase 1 \\
\hline 3949 & LDLR & -- & -2.10 & $3.51 \mathrm{E}-12$ & $\begin{array}{l}\text { low density lipoprotein receptor (familial } \\
\text { hypercholesterolemia) }\end{array}$ \\
\hline 8613 & PPAP2B & -- & -2.03 & $6.48 \mathrm{E}-04$ & $\begin{array}{l}\text { phosphatidic acid phosphatase type 2B, transcript } \\
\text { variant } 1\end{array}$ \\
\hline 1594 & CYP27B1 & -- & -2.01 & 4.56E-08 & $\begin{array}{l}\text { cytochrome } \mathrm{P} 450 \text {, family } 27 \text {, subfamily } \mathrm{B} \text {, } \\
\text { polypeptide } 1 \text {, nuclear gene encoding mitochondrial } \\
\text { protein }\end{array}$ \\
\hline 55902 & ACSS2 & -- & 2.07 & 1.54E-06 & $\begin{array}{l}\text { acyl-CoA synthetase short-chain family member } 2 \text {, } \\
\text { transcript variant } 2\end{array}$ \\
\hline 116255 & MOGAT1 & -- & 2.36 & 8.48E-06 & monoacylglycerol O-acyltransferase 1 \\
\hline \multicolumn{6}{|c|}{ beta-oxidation } \\
\hline 8660 & IRS2 & -2.14 & -2.15 & 7.03E-05 & insulin receptor substrate 2 (IRS2) \\
\hline \multicolumn{6}{|c|}{ Long-chain and unsaturated fatty acid metabolism } \\
\hline 5743 & PTGS2 & -4.50 & -3.79 & $2.54 \mathrm{E}-11$ & $\begin{array}{l}\text { prostaglandin-endoperoxide synthase } 2 \\
\text { (prostaglandin } \mathrm{G} / \mathrm{H} \text { synthase and cyclooxygenase) }\end{array}$ \\
\hline 552 & AVPR1A & -3.09 & -3.32 & $6.75 \mathrm{E}-07$ & arginine vasopressin receptor $1 \mathrm{~A}$ \\
\hline 7132 & TNFRSF1A & -2.16 & -- & $6.90 \mathrm{E}-11$ & $\begin{array}{l}\text { tumor necrosis factor receptor superfamily, member } \\
1 \mathrm{~A}\end{array}$ \\
\hline 2678 & GGT1 & 2.01 & -- & 1.67E-06 & gamma-glutamyltransferase 1, transcript variant 1 \\
\hline 3992 & FADS1 & 2.49 & 2.09 & $9.61 \mathrm{E}-06$ & fatty acid desaturase 1 \\
\hline 9415 & FADS2 & 2.81 & -- & 1.07E-04 & fatty acid desaturase 2 \\
\hline 641371 & ACOT1* & -- & -2.73 & 3.80E-02 & acyl-CoA thioesterase 1 \\
\hline
\end{tabular}

HC: healthy controls, SS: simple steatosis, NASH: nonalcoholic steatohepatitis,

Gene expression levels are given as fold-changes between two groups. --: not significant in two-group comparison (post-hoc $p$-value $\geq 0.05$ ) and/or less than 2 -fold up- or down-regulation. The q-value is the Benjamini-Hochberg corrected $p$-value.

* The only gene differentially expressed between SS and NASH related to the processes above was acylCoA thioesterase 1 (ACOT1) (2.99 fold up-regulated in NASH vs. SS). 
Table 4: Fatty acid profiles in hepatic and red blood cell total lipids in healthy controls and patients with simple steatosis or non-alcoholic steatohepatitis

\begin{tabular}{|c|c|c|c|c|}
\hline \multirow[b]{3}{*}{ Fatty acid } & \multicolumn{4}{|c|}{$\%$ of total lipids } \\
\hline & \multicolumn{2}{|c|}{ Hepatic fatty acids } & \multicolumn{2}{|c|}{ Red blood cell fatty acids } \\
\hline & $\begin{array}{c}\text { SS } \\
(n=13)\end{array}$ & $\begin{array}{l}\text { NASH } \\
(n=15)\end{array}$ & $\begin{array}{c}\text { SS } \\
(n=7)\end{array}$ & $\begin{array}{l}\text { NASH } \\
(\mathrm{n}=9)\end{array}$ \\
\hline Total SAT & $40.51 \pm 5.27$ & $42.46 \pm 4.31$ & $40.53 \pm 2.52$ & $40.96 \pm 3.69$ \\
\hline Total MUFA & $33.31 \pm 6.79$ & $35.94 \pm 4.97$ & $19.74 \pm 1.23$ & $19.31 \pm 1.52$ \\
\hline Total PUFA & $24.06 \pm 3.37$ & $19.48 \pm 4.34^{\star \star}$ & $36.72 \pm 2.61$ & $36.81 \pm 4.56$ \\
\hline Total n6 PUFA & $20.71 \pm 2.67$ & $17.11 \pm 3.91$ ** & $30.32 \pm 1.43$ & $31.07 \pm 4.07$ \\
\hline Total n3 PUFA & $3.32 \pm 1.40$ & $2.33 \pm 0.65$ * & $5.87(3.41)$ & $5.40(0.99)$ \\
\hline Total n6/n3 & $7.20 \pm 2.70$ & $7.52 \pm 1.35$ & $5.16 \pm 1.48$ & $5.94 \pm 1.71$ \\
\hline Total trans fatty acids & $2.31(1.52)$ & $1.80(1.94)$ & $3.01 \pm 0.89$ & $2.92 \pm 0.84$ \\
\hline 16:0 (palmitic acid) & $30.19(6.01)$ & $31.32(1.99)$ & $23.74 \pm 1.54$ & $23.98 \pm 2.45$ \\
\hline 18:0 (stearic acid) & $8.86 \pm 2.35$ & $7.64 \pm 1.60$ & $12.97 \pm 1.61$ & $13.64 \pm 1.52$ \\
\hline 16:1n7 (palmitoleic acid) & $2.63 \pm 0.83$ & $3.16 \pm 0.77$ & $0.55 \pm 0.21$ & $0.98 \pm 0.17$ \\
\hline 18:1n9 (oleic acid) & $27.13 \pm 6.23$ & $29.51 \pm 4.81$ & $14.59 \pm 1.41$ & $14.71 \pm 1.21$ \\
\hline 18:2n6 (linoleic acid) & $15.41 \pm 2.69$ & $13.45 \pm 2.90$ & $13.62 \pm 1.05$ & $14.02 \pm 1.71$ \\
\hline 18:3n6 ( $\gamma$-linolenic acid) & $0.30 \pm 0.21$ & $0.24 \pm 0.22$ & $0.50(0.77)$ & $0.24(0.57)$ \\
\hline 18:3n3 ( $\alpha$-linolenic acid) & $0.86 \pm 0.31$ & $0.94 \pm 0.27$ & $0.27 \pm 0.08$ & $0.29 \pm 0.04$ \\
\hline 20:3n6 (dihomo- $\gamma$-linolenic acid) & $0.80 \pm 0.26$ & $0.57 \pm 0.31$ * & $1.52 \pm 0.25$ & $1.72 \pm 0.29$ \\
\hline $20: 4 n 6(A A)$ & $3.99 \pm 1.75$ & $2.60 \pm 1.13$ * & $10.75(3.22)$ & $12.52(3.87)$ \\
\hline 20:5n3 (EPA) & $0.17(0.36)$ & $0.12(0.25)$ & $0.76(0.48)$ & $0.49(0.18)$ \\
\hline 22:6n3 (DHA) & $1.73(1.81)$ & $1.13(0.67)$ & $3.19(2.89)$ & $2.77(1.15)$ \\
\hline $\mathrm{EPA}+\mathrm{DHA}$ & $2.20 \pm 1.33$ & $1.24 \pm 0.62$ * & 4.05 (3.32) & $3.16(1.03)$ \\
\hline$\overline{A A} / L A$ & $0.27 \pm 0.13$ & $0.20 \pm 0.08$ & $0.83 \pm 0.16$ & $0.82 \pm 0.12$ \\
\hline$(\mathrm{EPA}+\mathrm{DHA}) / \mathrm{ALA}$ & $2.41(2.05)$ & $1.42(1.14)$ & $17.54(19.1)$ & $11.30(4.47)$ \\
\hline $\begin{array}{l}\Delta 5 \text { desaturase index } \\
20: 4 n 6 / 20: 3 n 6\end{array}$ & $4.86 \pm 1.05$ & $4.05 \pm 1.11$ & $6.73 \pm 1.80$ & $6.27 \pm 1.39$ \\
\hline $\begin{array}{l}\Delta 6 \text { desaturase index } \\
18: 3 n 6 / 18: 2 n 6\end{array}$ & $0.02 \pm 0.01$ & $0.02 \pm 0.01$ & $0.04(0.07)$ & $0.02(0.04)$ \\
\hline
\end{tabular}

SS: simple steatosis, NASH: nonalcoholic steatohepatitis, SAT: saturated fatty acids, MUFA: monounsaturated fatty acids, PUFA: polyunsaturated fatty acids AA: arachidonic acid, EPA: eicosapentaenoic acid, DHA:

docosahexaenoic acid, LA: linolenic acid, ALA: $\alpha$-linolenic acid

Values are median (interquartile range) or mean \pm SD.

* asterisks show significant differences between SS and NASH, ${ }^{*} p<0.05,{ }^{* *} p<0.01$

Unpaired t- test was used for normally distributed data and Wilcoxon test for data with skewed distribution. 
Table 5: Spearman correlations for hepatic gene expression and hepatic long-chain polyunsaturated fatty acids in patients with simple steatosis or nonalcoholic steatohepatitis

\begin{tabular}{|c|c|c|c|c|c|c|}
\hline \multirow[b]{3}{*}{$\begin{array}{l}\text { Gene } \\
\text { Symbol }\end{array}$} & \multicolumn{6}{|c|}{ Spearman rho } \\
\hline & \multicolumn{3}{|c|}{ EPA+DHA } & \multicolumn{3}{|c|}{ AA } \\
\hline & $\begin{array}{c}\text { NAFLD } \\
\text { (SS+NASH) }\end{array}$ & SS & NASH & $\begin{array}{c}\text { NAFLD } \\
\text { (SS+NASH) }\end{array}$ & SS & NASH \\
\hline \multicolumn{7}{|l|}{ Fibrosis } \\
\hline MMP9 & $-0.448 *$ & -0.385 & -0.418 & -0.275 & -0.137 & -0.334 \\
\hline CXCR4 & -0.322 & 0.132 & $-0.664^{* *}$ & -0.269 & 0.253 & $-0.617^{*}$ \\
\hline CCL2 & 0.227 & -0.044 & $0.543^{*}$ & 0.297 & 0.225 & 0.452 \\
\hline \multicolumn{7}{|c|}{ Cellular response to oxidative stress } \\
\hline CDC2 & $-0.470 *$ & -0.533 & -0.064 & $-0.489 * *$ & -0.549 & -0.159 \\
\hline FOS & 0.248 & 0.538 & 0.146 & 0.365 & $0.621^{*}$ & 0.159 \\
\hline \multicolumn{7}{|c|}{ Lipogenesis } \\
\hline GCK & $-0.393^{*}$ & -0.396 & -0.343 & $-0.510^{* *}$ & -0.533 & -0.377 \\
\hline JUB & $-0.411^{*}$ & -0.462 & 0.025 & $-0.407^{*}$ & $-0.599 *$ & 0.164 \\
\hline PNPLA3 & -0.301 & -0.159 & -0.121 & $-0.378 *$ & -0.363 & -0.238 \\
\hline FADS2 & $-0.409 *$ & -0.516 & -0.200 & -0.327 & -0.412 & -0.181 \\
\hline GGT1 & -0.166 & -0.533 & 0.211 & -0.211 & $-0.676^{*}$ & 0.120 \\
\hline CYP7A1 & -0.096 & -0.379 & 0.514 & -0.155 & -0.549 & $0.547^{*}$ \\
\hline MTMR4 & -0.007 & -0.264 & 0.043 & -0.032 & $-0.604^{*}$ & 0.206 \\
\hline ACSM1 & 0.265 & 0.692 * & 0.293 & 0.044 & 0.418 & 0.130 \\
\hline $\mathrm{CH} 25 \mathrm{H}$ & 0.284 & -0.055 & 0.550 * & 0.236 & 0.247 & 0.254 \\
\hline SIK1 & $0.380^{*}$ & 0.516 & 0.318 & 0.238 & 0.429 & 0.046 \\
\hline \multicolumn{7}{|c|}{ Long-chain and unsaturated fatty acid metabolism } \\
\hline FADS2 & $-0.409 *$ & -0.516 & -0.200 & -0.327 & -0.412 & -0.181 \\
\hline GGT1 & -0.166 & -0.533 & 0.211 & -0.211 & $-0.676^{*}$ & 0.120 \\
\hline \multicolumn{7}{|c|}{ Different between SS and NASH } \\
\hline PEG10 & $-0.501^{* *}$ & -0.357 & -0.354 & $-0.525^{* *}$ & -0.549 & -0.345 \\
\hline EEF1A2 & -0.365 & -0.280 & 0.093 & $-0.427^{*}$ & -0.313 & 0.005 \\
\hline MT1A & $0.452^{*}$ & 0.401 & 0.075 & $0.447^{\star}$ & $0.560^{(*)}$ & -0.046 \\
\hline DIO3OS & $0.419^{*}$ & 0.324 & 0.068 & $0.455^{*}$ & $0.621^{*}$ & 0.063 \\
\hline
\end{tabular}

SS: simple steatosis, NASH: nonalcoholic steatohepatitis, EPA: eicosapentaenoic acid, DHA: docosahexaenoic acid, $A A$ : arachidonic acid

Highlighted cells mark significant correlations, light grey: positive, dark grey: negative

* asterisks show significant correlations, ${ }^{*} p<0.05,{ }^{* *} p<0.01,{ }^{(*)} p=0.05$

No gene related to chronic inflammatory response or beta-oxidation was significantly correlated with EPA+DHA or AA. 


\section{Figures}

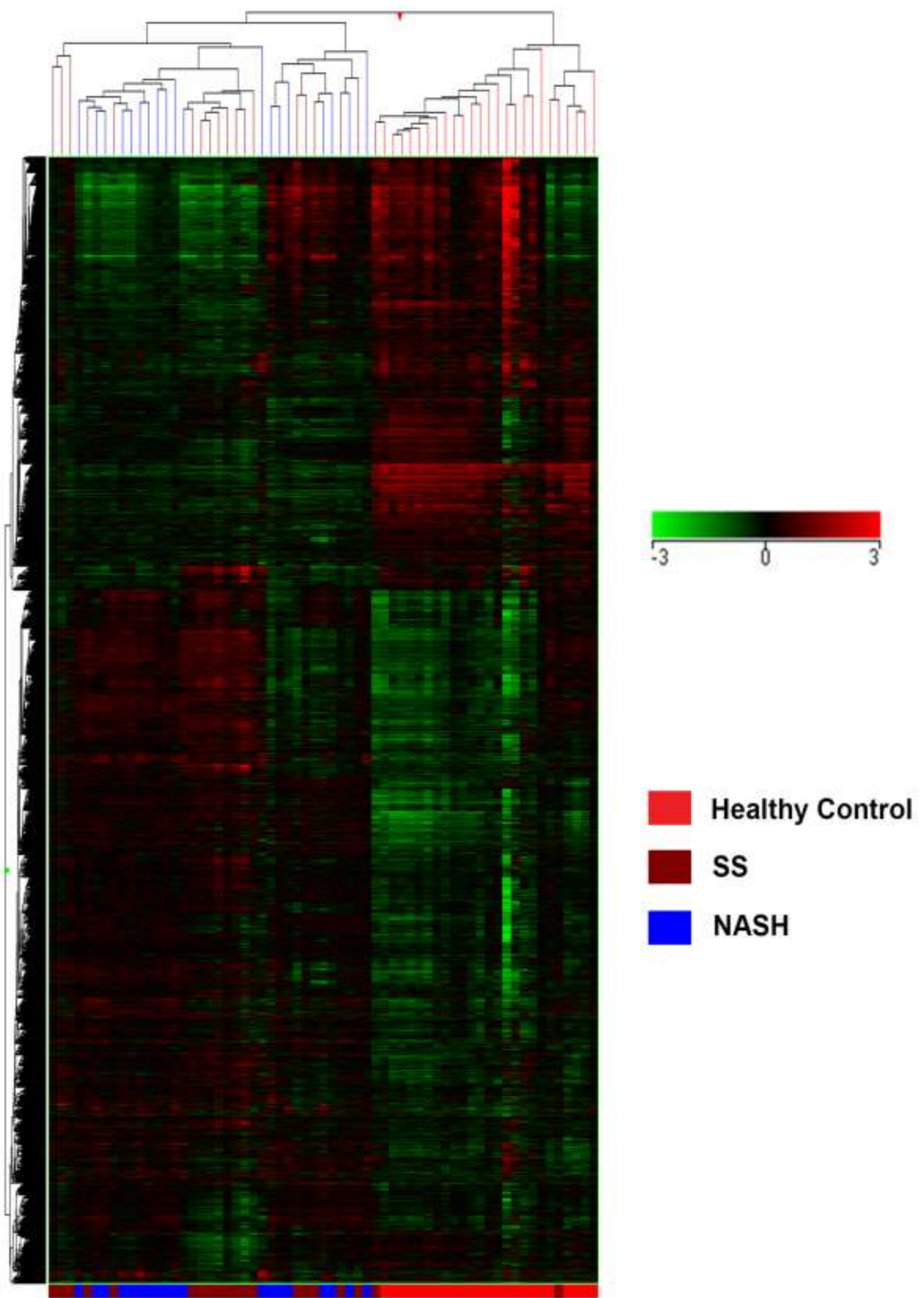


Figure 1: Heat map illustrating unsupervised hierarchical clustering of hepatic gene expression in patients with simple steatosis (SS) or nonalcoholic steatohepatitis (NASH) and healthy controls (HC). Hepatic gene expression was measured using the Whole Genome Gene DASL HT Assay (Illumina Inc., San Diego, CA, USA) and the Illumina Human HT-12 V4 BeadChip. ANOVA with Tukey's Post hoc test showed 10,350 significantly varying probes among NASH, SS, and HC. The probes were clustered for visualization. The rows represent genes and columns represent hybridized samples. The intensity of the color symbolizes the ratio between each value and the average expression of each gene across all samples. Red indicates higher and green indicates lower mRNA abundance in a sample. The color coded legend underneath shows the groups, whereby red is HC, brown is SS, and blue is NASH. The heatmap shows reasonable but not perfect separation of the three groups based on hepatic gene expression profile. 
a

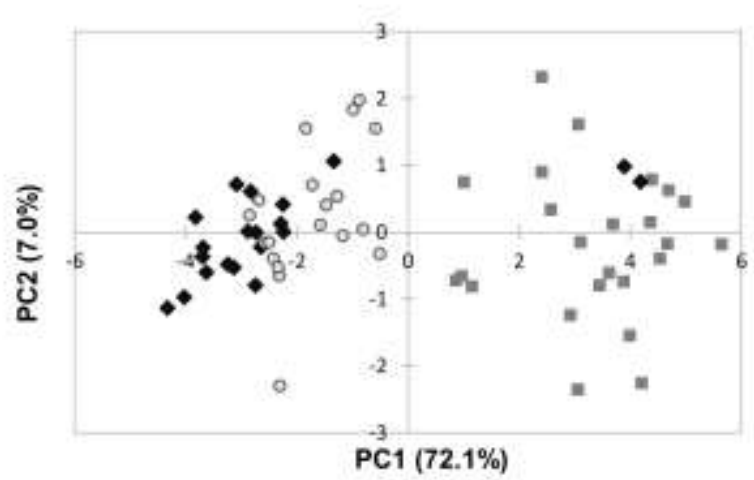

C Genes related to lipogenesis and beta-oxidation

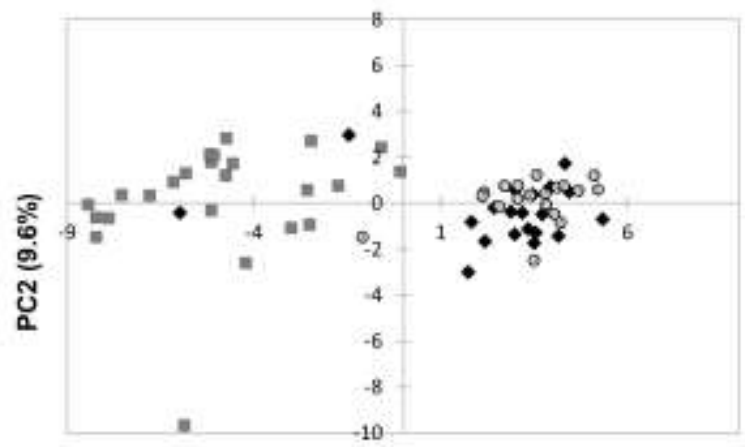

PC1 $(57.2 \%)$

\section{b Genes related to oxidative stress and chronic inflammatory response}

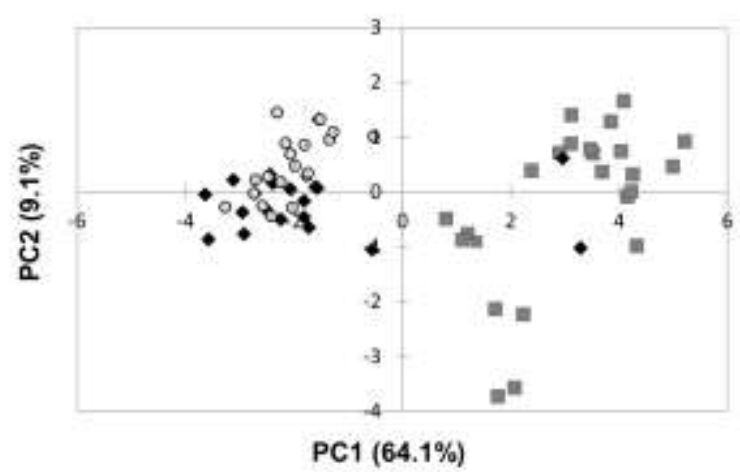

\section{d Genes related to long-chain and unsaturated fatty acid metabolism}

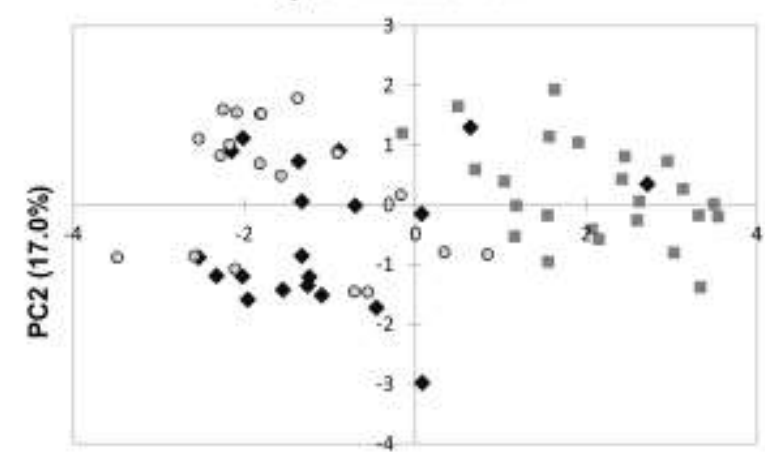

PC1 $(55.9 \%)$

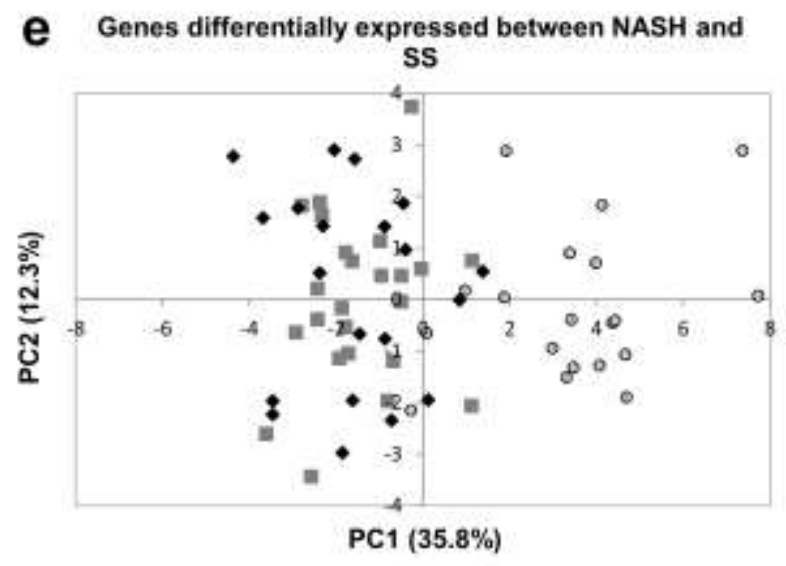


Figure 2: Principal component analysis for hepatic gene expression in patients with simple steatosis (SS) or nonalcoholic steatohepatitis (NASH) and healthy controls (HC). Points represent values for individual participants (HC: grey squares, SS: black diamonds, NASH: grey circles). Gene sets included a) 13 genes related to fibrosis; b) 13 genes related to chronic inflammation and cellular response to oxidative stress; c) 38 genes related to lipogenesis and 1 gene related to beta-oxidation; d) seven genes related to long-chain and unsaturated fatty acid metabolism; Gene sets for a) to d) were derived from the literature (Supplementary Table S1) and differentially expressed genes corresponding to these sets as listed in Table 2 were included in the principal component analysis. The gene sets show a clear differentiation between patients (SS and NASH) from HC. e) This analysis included the 22 genes that are differentially expressed between NASH and SS. Here the patients with SS are grouping with $\mathrm{HC}$, and both are different from NASH. 

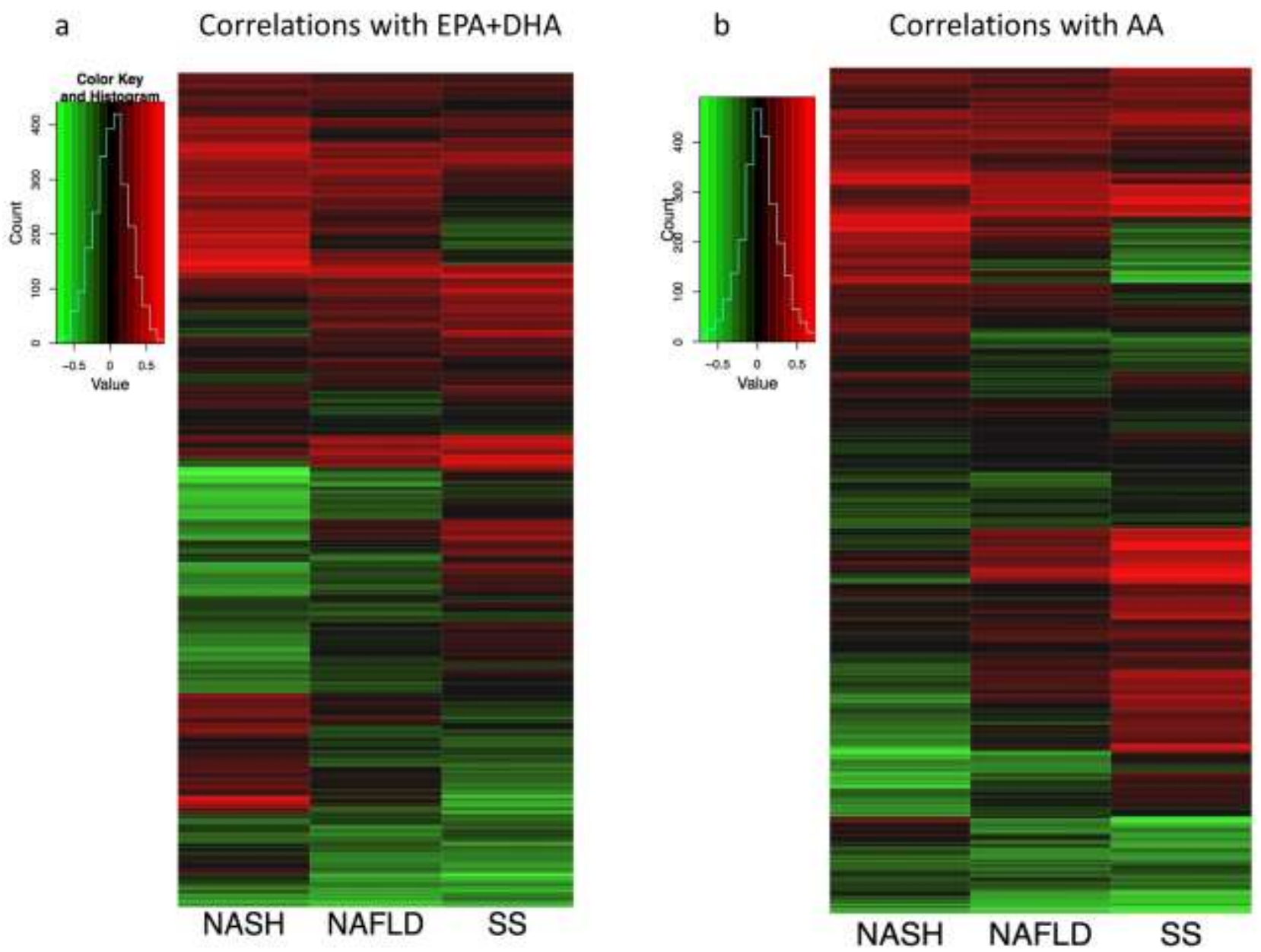

Figure 3: Correlations between gene expression and long-chain polyunsaturated fatty acids in the liver. The heatmaps illustrate correlations between hepatic gene expression and a) n-3 index (eicosapentaenoic acid (EPA) + docosahexaenoic acid (DHA)) as well as b) arachidonic acid (AA) in hepatic total lipids in patients with simple steatosis (SS), nonalcoholic steatohepatitis (NASH), or in both groups combined (NAFLD). All 822 probes that are differentially expressed among SS, NASH, and healthy controls were included, and the heatmaps were generated using unsupervised hierarchical clustering. Genes are listed vertically. The color intensity corresponds to the correlation coefficient (red: positive correlation, green negative correlation). The two heatmaps show a clear differentiation between SS and NASH as well as the whole group of NAFLD patients combined based on the correlation coefficients between mRNA levels and fatty acid abundance in hepatic total lipids, which means for many genes, the relationship differs depending on the patient group examined. 